\title{
SISTEMA NACIONAL DE INOVAÇÃO: AS POLÍTICAS TECNOLÓGICAS E DE INOVAÇÃO DA CORÉIA DO SUL
}

\author{
THAÍS CAMILA PABIS \\ Bacharel em Ciências Econômicas pela Universidade Federal de Santa Catarina - UFSC
}

\section{RESUMO}

O objetivo deste artigo é compreender o papel das políticas tecnológicas e de inovação na criação e no desenvolvimento do Sistema Nacional de Inovação sul-coreano. Este processo envolveu a rápida transformação de um dos mais pobres países do mundo em uma economia industrializada e moderna. Dentre as forças propulsoras da dinâmica de transição da imitação à inovação do país, destaca-se o forte papel governamental. O referencial analítico de Paradigma Tecnoeconômico e Janelas de Oportunidade foram brevemente apresentados como momentos específicos a serem observados por países em desenvolvimento. Com base nisso, o processo histórico de desenvolvimento da Coréia do Sul foi apresentado e discutido. Complementarmente, indicadores estatísticos, disponibilizados pela Organization for Economic Cooperation and Development (OECD) e United Nations Conference on Trade and Development (UNCTAD), foram utilizados. Como resultado, o crescente aprimoramento da capacidade tecnológica do país pode ser observado no tempo, destacando-se o papel das políticas industriais e de inovação no processo. Finalmente, a pesquisa sobre o foco das ações recentes revelou as ideias de economia criativa e economia verde como o sentido da estratégia tecnológica para desenvolvimento da economia sul-coreana.

Palavras-chave: Coréia do Sul; Sistema Nacional de Inovação; Política tecnológica; Inovação.

\begin{abstract}
The purpose of this article is to understand the role of technology and innovation policy in the creation and development of the National Innovation System of South Korea. This process involved the rapid transformation of one of the poorest countries in the world in an industrialized and modern economy. Among the driving forces of the dynamic transition from imitation to innovation in the country, it stands out the strong government role. The analytical framework of Techno-economic Paradigm and Windows of Opportunity were briefly presented as specific moments to be observed by developing countries. Based on this, the historical process of development in South Korea was presented and discussed. In addition, statistical indicators provided by the Organization for Economic Cooperation and Development (OECD) and United Nations Conference on Trade and Development (UNCTAD), were used. As a result, the increasing improvement of the technological capacity of the country can be seen in the time, highlighting the role of industrial policy and innovation in the process. Finally, research on the recent actions focus revealed ideas of creative economy and green economy as the direction of technology strategy for development of the South Korean economy.
\end{abstract}

Keywords: South Korea; National Innovation System; Technology policy; Innovation.

Área ABEIN: 8; 6.

Código JEL: O38; O25. 


\section{INTRODUÇÃO}

O desenvolvimento econômico pode ser visto como um conjunto de ciclos econômicos e inovativos com intensidades e durações diferentes, desejado pelas economias nacionais que buscam o seu aprimoramento, independentemente do grau de emparelhamento tecnológico em que estas se localizam. Estes ciclos econômicos são compostos por revoluções tecnológicas ${ }^{1}$, as quais expõem o processo de reacoplamento e convergência de uma nova onda de desenvolvimento na economia. Isto é, o conflituoso processo de difusão de uma nova tecnologia na economia, a qual é vista como polêmica ao passo que choca-se com a tecnologia anteriormente empregada e que agora encontra-se obsoleta.

O conceito de revolução tecnológica dita um modelo de adaptação social, no qual as grandes firmas existentes são protagonistas do assassinato do paradigma vigente, tanto como agentes quanto como vítimas, a ser executado por meio da introdução de uma nova tecnologia. Pérez (2009) ressalta uma clara definição de que revoluções tecnológicas representam um conjunto de inovações capazes de criar trajetórias tecnológicas, nas quais as transformações sociais são estimuladas. Tais revoluções compreendem aglomerados de sistemas de tecnologia inter-relacionados, que ultrapassam os limites das indústrias que os introduzem, transformam a economia, elevam o nível esperado de produtividade, rejuvenescem as indústrias maduras e abrem novas trajetórias de inovação. Estas transformações têm o poder de mudar as relações entre os indivíduos ao promover um novo "senso comum” ou paradigma tecnoeconômico.

A mudança de paradigma exige a renúncia dos velhos caminhos antes utilizados para alcançar o sucesso e o desprendimento das experiências adquiridas, para então dedicar-se à nova tecnologia. Este processo representa uma trajetória dolorosa, lenta e cheia de riscos e obstáculos, embora efetue o rejuvelhecimento de toda a estrutura produtiva, de modo com que as indústrias maduras e então atualizadas possam comportar-se novamente como indústrias novas no mercado, tanto em termos de dinamismo, produtividade quanto de rentabilidade. A transição de um paradigma para outro representa o momento ideal para que as economias inseridas no novo sistema de tecnologia possam auferir as melhores oportunidades de desenvolvimento. Nele as tecnologias maduras do paradigma anterior tentam ao máximo superar as limitações ao crescimento de sua produtividade e de seus mercados, enquanto que as novas tecnologias se expandem, florescem e crescem rapidamente, auferindo grandes margens de benefício.

Destarte, uma janela temporária de oportunidade ${ }^{2}$ é aberta no atual paradigma aos países em processo de catching-up que, após décadas de esforços para conquistar tecnologias maduras, atingem determinado nível de capacidade produtiva e de vantagens locacionais, além de suficiente dotação de pessoas qualificadas em novas tecnologias. No entanto, é fundamental que as economias saibam reconhecer estas novas oportunidades de desenvolvimento e sejam competentes o suficiente para criar as condições sociais, a vontade política e as estratégias adequadas necessárias para que possam aproveitálas. As mudanças na trajetória tecnológica de países avançados criam oportunidades favoráveis para as economias que buscam recuperar o seu atraso, o que torna a comunidade internacional uma das fontes mais importantes para o aprendizado tecnológico. Isto posto, conforme Pérez (2001), é fato de que não existe uma fórmula mágica para que os países possam alcançar o desenvolvimento econômico sem o próprio domínio tecnológico. Logo, as oportunidades de desenvolvimento podem ser descritas como um alvo em movimento e a tecnologia como a condição necessária de viabilidade das políticas desenvolvimentistas.

Assim, este trabalho tem o intuito de investigar a criação e o desenvolvimento do Sistema Nacional de Inovação (SNI) da Coréia do Sul em perspectiva histórica, tendo em vista a rápida industrialização do país, exemplo do hiato tecnológico que separa países desenvolvidos dos em desenvolvimento. O processo envolveu a transformação econômica de uma economia baseada na agricultura de subsistência para uma economia industrializa e moderna. No período em tela, em menos de trinta anos a Coréia do Sul transformou-se em uma das principais potências tecnológicas da atualidade.

\footnotetext{
${ }^{1}$ Ver sobre Teoria das Grandes Ondas de Desenvolvimento em Pérez (2004).

${ }^{2}$ As oportunidades de desenvolvimento aqui citadas correspondem àquelas que se manifestam e se modificam conforme ocorrem as sucessivas revoluções tecnológicas (PÉREZ; SOETE,1988, p.476).
} 
No entanto, segundo experiências de economias industrializadas, as economias nacionais dependem de mudanças tecnológicas para alcançar tal nível de desenvolvimento, as quais em longo prazo promovem o crescimento econômico. Até 1961, a Coréia do Sul enfrentava crises e dificuldades então características de países pobres. A partir da década de 1970, as primeiras bases do que atualmente é reconhecido como o moderno Sistema Nacional de Inovação sul-coreano foram criadas.

O forte papel desenvolvimentista do governo foi fundamental para a trajetória de crescimento econômico baseada em tecnologia na Coréia do Sul. Através do fomento aos conglomerados empresarias - os chaebols, à engenharia reversa, aos investimentos em Pesquisa e Desenvolvimento, aos institutos de pesquisa e ao fortalecimento do mercado interno, então efetuados pelo governo sul-coreano, a inovação pode ser estimulada ao longo dos anos no país. A Coréia do Sul tornou-se uma economia mais aberta e focada na produção de alta tecnologia ainda na década de 1980. Em meio à crises e desafios, a economia sul-coreana adotou, em 2008, uma nova estratégia de desenvolvimento apoiada na promoção da eficiência energética, a política de crescimento verde e de baixo carbono. Já em 2013, com a instituição de uma economia criativa no país, a prioridade do governo sul-coreano passou a ser a transformação da Coréia do Sul em uma economia de inovação avançada.

Por essa razão, a questão mais pertinente é como ciência e tecnologia, que parecem ser a chave para o desenvolvimento industrial em países avançados, podem ser efetivamente usadas para o desenvolvimento social e econômico nas regiões menos desenvolvidas do mundo (KIM, 2005, p.16).

O estudo de casos de sucesso de países em desenvolvimento, a cerca de sua estrutura industrial, nos guia na necessidade da formação de possíveis modelos ou caminhos para implementação e desenvolvimento de Sistemas Nacionais de Inovação. Embora não exista um modelo ideal de SNI, por meio das experiências nacionais na formulação de um sistema, pode-se elaborar um conjunto de decisões e políticas satisfatórias, as quais contribuíram ou ainda contribuem para o processo desenvolvimentista no intuito de promover a economia da inovação. Logo, a compreensão do processo de industrialização e construção do setor de alta tecnologia sul-coreano são elencados como objetivos deste trabalho. As políticas tecnológicas e de inovação que instigaram a indústria da Coréia do Sul, especialmente as de alta intensidade tecnológica, serão aqui debatidas na intensão de efetuar uma análise das principais medidas desenvolvimentistas tomadas pelo país ao iniciar a consolidação do seu SNI e das medidas que hoje o fomentam.

\section{A EXPERIÊNCIA SUL-COREANA}

Poucos países em processo de catching-up conseguem acompanhar o ritmo competitivo imposto pelas economias avançadas no paradigma tecnoeconômico vigente ou, principalmente, conseguem identificar as suas vantagens frente à estas últimas. Entre as experiências das economias que estão em processo de catching-up ou que passaram pelo mesmo, um país merece grande destaque. A Coréia do Sul foi capaz de identificar em uma janela de oportunidade a construção de um futuro próspero e agiu de forma eficiente para conquistar o desenvolvimento econômico então desejado. Os sul-coreanos emergiram de uma economia de subsistência com base técnica inferior, sem recursos naturais em abundância e como o mais pobre dos países de industrialização recente para uma economia de rápido crescimento industrial nos últimos cinquenta anos. A perseverança em industrializar o país fez dos sulcoreanos bons inovadores, em virtude das estratégias desenvolvidas para ajustar as invenções estrangeiras conforme as necessidades de sua própria indústria, que, consequentemente, proporcionou importantes descobertas e criações. Ao decorrer dos anos, a Coréia do Sul transformou-se em uma economia detentora de um parque industrial diversificado com tecnologia avançada e, ainda, de índices econômicos de países desenvolvidos.

O desenvolvimento tecnológico da economia sul-coreana teve início com a imitação da tecnologia 
estrangeira, a qual, por meio da engenharia reversa ${ }^{3}$, foi a principal forma de aquisição de aptidões tecnológicas. A imitação foi inicialmente adotada na década de 1960 e estendeu-se até 1979. O intuito era propor a imitação reprodutiva, na qual o imitador não dispõe de uma margem competitiva nos preços, dado que os seus custos de produção são menores que os custos dos criadores do produto. Dessa forma, devido à tecnologia disponível e de fácil execução, a estratégia da imitação reprodutiva obteve grande sucesso nos primeiros estágios do processo de catching-up da Coréia do Sul e, a partir da década de 1970, instituiu as primeiras bases do moderno Sistema Nacional de Inovação sul-coreano.

A década de 1980 foi marcada por um período de transição ou de internalização para o segundo estágio de desenvolvimento tecnológico, que segue até o momento atual e é denominado de estágio da criação. A partir de 1990, os engenheiros sul-coreanos já encontravam-se capazes, por meio de esforços locais, de construir novas fábricas ou desenvolver produtos, conforme Lee (2005). As aptidões tecnológicas conquistadas pelas empresas sul-coreanas foram, em sua maioria, consequência do forte compromisso do governo com a industrialização. Logo, o governo do presidente Park Chung-hee, de 1963 à 1979, foi o arquiteto do início do desenvolvimento industrial da Coréia do Sul por meio de um governo altamente centralizado e forte, capaz de planejar e excetuar ambiciosos programas de desenvolvimento econômico.

\subsection{A Demanda por Tecnologia: Políticas Industriais}

Para promover as exportações, superar a desvantagem de um mercado interno pequeno e explorar tecnologias estrangeiras maduras, o governo sul-coreano criou intencionalmente grandes empresas chamadas de chaebols. Isto é, conglomerados de empresas de diferentes áreas de negócios, pertencentes a uma ou duas famílias e administrados pelos seus membros. Os chaebols foram essenciais na expansão e intensificação das atividades de P\&D da Coréia do Sul nas décadas de 1980 e 1990, e, também decisivos na aquisição de capacidade tecnológica do país, pois detinham recursos organizacionais e tecnológicos para identificar e financiar a transferência de tecnologias estrangeiras, assim como assimilar e aperfeiçoar as tecnologias importadas.

Isto posto, por meio dos bancos comerciais então estatizados, o governo concedeu aos chaebols divisas em moeda estrangeira e linhas de financiamento preferenciais com taxas abaixo das taxas de mercado, além de auxiliá-los nos projetos de substituição de importações mediante ao acesso à empréstimos estrangeiros. Com o objetivo de suscitar o crescimento destas empresas, o governo estendeu ainda incentivos fiscais para $P \& D$ e redução ou eliminação de direitos aduaneiros sobre equipamentos de P\&D. Não obstante, o governo instituiu as políticas de substituição de importações e de promoção de exportações como principais políticas industriais aos ramos da indústria considerados estratégicos. A demanda por transferência de tecnologia estrangeira foi então criada através do protecionismo econômico imposto no país, o qual pode promover o surgimento de novos ramos industriais e a introdução de produtos mais sofisticados nos ramos já existentes.

Em contrapartida, a mão do Estado na Coréia do Sul não foi assim tão amigável. Ela exigia resultados e muitas vezes punia severamente as empresas que apresentassem um fraco desempenho na indústria. Medidas autoritárias foram estipuladas e impostas aos chaebols, como a instituição das metas de exportação durante a década de 1960, que pressionaram as empresas com metas ambiciosas de desenvolvimento. Embora, em outros momentos, a mão do Estado tenha sido generosa com os chaebols que demonstrassem ótimos resultados, presenteando-os com novas licenças em outras indústrias. Já as vantajosas licenças de importação eram atribuídas apenas às empresas com o melhor desempenho no campo das exportações. Ao impor a sua disciplina, o governo sul-coreano presenciou a sobrevivência de poucas empresas no sistema. A maioria dos chaebols eram pequenos e se expandiram de forma dinâmica em meio a tumultos políticos. Como resultado, apenas três empresas - Samsung, Luck Gold Star e Ssangyong - das dez maiores em 1965 permaneceram na lista dos maiores chaebols dez anos depois.

Segundo Kim (2005b), a principal consequência do estímulo governamental aos chaebols pode ser representado através da dificuldade com que as Pequenas e Médias Empresas (PME) sofreram ao

\footnotetext{
${ }^{3}$ A engenharia reversa empregada na Coréia do Sul não fez uso da violação de patentes ou do uso de pirataria de propriedade intelectual. Kim (2005).
} 
desenvolver-se. O fomento às PME veio tardiamente na década de 1980 , por meio da concessão de empréstimos e da criação de mercados direcionados à estas empresas. O governo começou a promover as PME, em especial as pequenas firmas baseadas em tecnologia, para sanar o desequilíbrio entre os grandes e pequenos setores de negócios. Estabeleceu também "santuários" para as PME ao designar 205 negócios à elas, nos quais nem as grandes empresas nem as suas filiais teriam permissão de entrar. As autoridades governamentais desenvolveram então o programa The Compulsory Lending Ratio, em que os bancos comerciais nacionais seriam obrigados a destinar cerca de 35\% do total de seus empréstimos às PME e os bancos locais ou regionais o total de $80 \%$ de seus empréstimos. O governo ainda tomou iniciativas para estabelecer a indústria de capital de risco quando o setor privado não tinha algum interesse em fazê-lo, como forma de promover o aparecimento de base tecnológica das pequenas empresas.

Por fim, graças ao uso de instrumentos tarifários do financiamento preferencial, da oferta de terrenos industriais baratos e do relaxamento de regulamentos antitrustes, os chaebols puderam seguir na direção do avanço tecnológico. Com as políticas de substituição de importações e de promoção de exportações, as empresas sul-coreanas foram direcionadas para um mercado internacional altamente competitivo e, para sobreviver as novas crises e oportunidades de negócios deste mercado, viram-se obrigadas à investir pesadamente no aprendizado tecnológico e na aquisição, assimilação e aperfeiçoamento de tecnologias estrangeiras. Assim, conforme Kim (2005b, p.456), "as empresas dos ramos orientados para a exportação aprenderam e cresceram mais rapidamente do que as empresas dos ramos de substituição das importações”.

Gráfico 1 - Total de Importações e Exportações de Bens e Serviços em porcentagem do PIB e Taxa de Crescimento do PIB da Coréia do Sul de 1970-2014

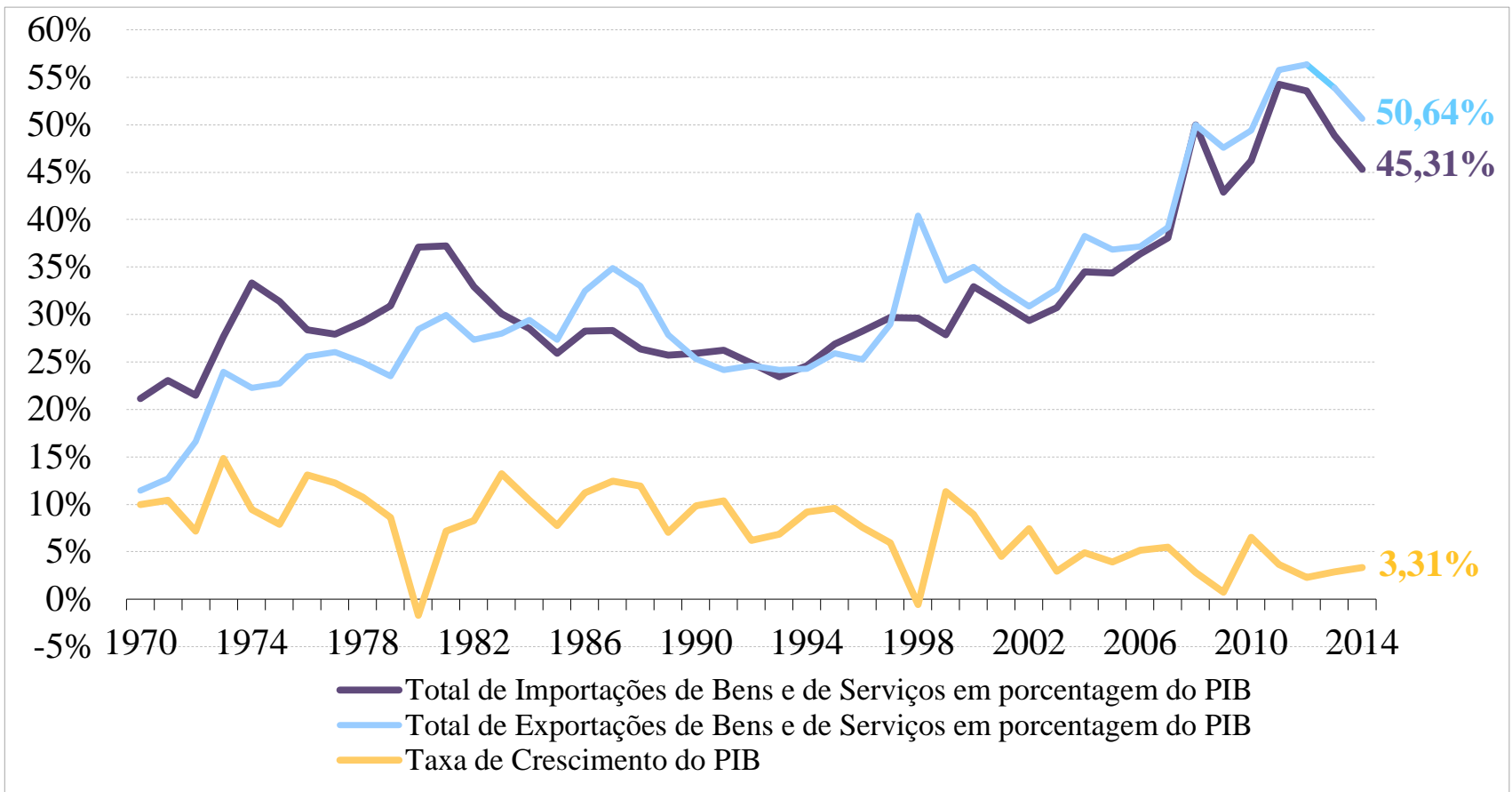

Fonte: Elaborado pela autora a partir de OECD (2016).

Entre os anos 1950 e 1960, a taxa de crescimento das exportações sul-coreanas representava 0,82\% e das importações 17,21\%. Os efeitos da política de substituição de importações e promoção das exportações podem ser observados entre os anos 1960 e 1970, nos quais as exportações tiveram um crescimento maior do que as próprias importações, 39,82\% contra 21,28\%. Conforme o Gráfico 1, embora o crescimento do PIB da Coréia do Sul em 1980 apresente taxa negativa em consequência da segunda crise do petróleo, as exportações do país representavam no mesmo ano US\$ 17 trilhões e suas importações US\$ 22 trilhões, ou seja, 27,22\% e 34,67\% do PIB respectivamente (OECD, 2016).

A partir de 1984, a curva de exportações em porcentagem do PIB ultrapassa a curva de importações, perdendo força após 1989. Em decorrência da crise financeira que atingiu o Leste Asiático em 1997, a Coréia do Sul presenciou novamente um crescimento negativo do seu PIB no ano de 1998, de 
-0,55\%. O país, entretanto, observou um salto em suas exportações de 28,98\% do PIB em 1997 para 40,39\% em 1998, enquanto as suas importações alcançavam apenas 29,60\% do PIB no mesmo ano. Em reflexo, a Coréia do Sul recuperou-se e cresceu 11,31\% em 1999.

No entanto, em decorrência da crise do subprime de 2008, o país confrontou-se com uma taxa de crescimento do PIB de apenas $0,71 \%$ no ano de 2009, muito inferior à sua taxa média de crescimento entre os anos de 1970 e 2000, de 9,6\%, de acordo com a OECD (2016). Após o choque, o PIB sulcoreano retomou os seus patamares de crescimento em uma taxa de 6,50\% no ano de 2010. Em 2014, o crescimento foi de 3,31\%. A taxa de crescimento das exportações se manteve à frente das importações entre as décadas 1970-1980, 1980-1990 e 1990-2000. O total de exportações e de importações do país atingiram US\$ 559 trilhões e US\$ 515 trilhões, respectivamente, em 2013. No mesmo ano, as importações atingiram uma taxa de crescimento negativa de $0,77 \%$, enquanto as exportações aumentavam em torno de 2,15\%. Em resultado, a Coréia do Sul passou do $101^{\circ}$ lugar entre os maiores países exportadores do mundo em 1962, para o $14^{\circ}$ em 1985 e para o $6^{\circ}$ lugar em 2013, ficando atrás apenas da China, EUA, Alemanha, Japão e Holanda (OECD, 2016) (UN COMTRADE, 2015).

O governo sul-coreano promoveu ainda, a partir de 1969, o desenvolvimento das Indústrias Químicas e Pesadas (IQPS), em que indústrias como a siderúrgica, petroquímica, eletrônica, de construção naval, de maquinaria pesada e de metais não-ferrosos foram criadas. Para isso, o próprio governo adotou o risco de crédito das empresas destes setores e fez os investimentos necessários - a partir da oferta de crédito com baixas taxas de juros do Fundo Nacional de Investimentos - para a consolidação das IQPS. A Coréia do Sul, assim como qualquer outro país em processo de catching-up, foi forçada à recorrer ao endividamento externo, pois não possuía uma poupança interna suficiente para poder efetuar os pesados investimentos em sua indústria.

Com a desaceleração geral da economia mundial e as medidas protecionistas adotadas nos EUA e na Europa da década de 1980, as exportações sul-coreanas foram afetadas negativamente e, em 1986, a Coréia do Sul foi obrigada a criar uma nova legislação para regular a propriedade intelectual e as patentes do próprio país. Assim, a economia sul-coreana perdeu a sua competitividade nos ramos industriais intensivos em mão-de-obra e de baixos salários, enfrentou problemas com a transferência de tecnologias - em especial as japonesas, e foi obrigada a vetar a engenharia reversa de produtos estrangeiros na indústria. $\mathrm{O}$ uso de royalties para intensificar os esforços tecnológicos em inovação foi então amplamente utilizado pelos chaebols, o que ocasionou um aumento de preços dos seus próprios produtos.

À medida que a transição do estágio da imitação para a inovação se concretizava na indústria sulcoreana, os inovadores do país começaram a demandar maior proteção às suas criações. Foi outorgada em 1986 a Lei Essencial de Patentes, em 1987 a Lei de Proteção dos Programas de Computador e em 1995 a nova Lei de Patentes foi criada. Cerca de 5 mil patentes foram requeridas em 1980 na Coréia do Sul, 25.820 patentes em 1990 e 78.499 em 1995 (KIM, 2005a). Já no ano de 2013, conforme o relatório The Evaluation Of Science And Technology Innovation Capacity (2013), os sul-coreanos conquistaram o quarto lugar mundial no ranking de número de registros de patentes.

Para reposicionar a economia sul-coreana, o governo adotou uma nova política de industrialização nas décadas de 1980 e 1990, sustentada na redução da intervenção governamental, inclusão de mecanismos de mercado e mudança estrutural nos ramos industriais mais baseados em tecnologia. Dentre as medidas estabilizadoras da nova política, destacam-se: a introdução de uma lei antitruste; a liberalização do mercado financeiro e do comercio exterior; a promoção das empresas de pequeno e médio porte; a liberalização dos investimentos estrangeiros; a desvalorização do won, a moeda sulcoreana; bem como a mudança da ênfase para atividades voltadas à inovação.

A liberalização do comércio exterior sul-coreano teve início ainda na década de 1970 e concretizou-se por volta de 1982. A razão dos subsídios líquidos da exportação em relação à taxa de câmbio alcançou 36,6 em 1963, 6,7 em 1970 e 0,4 em 1982. Mesmo sem os subsídios governamentais, as empresas sul-coreanas já eram capazes de competir no mercado internacional nas décadas de 1980 e 1990. Em 1984, a liberalização da política de importação foi concretizada através da redução geral e gradual dos impostos sobre produtos importados instituída pela Lei de Reforma Tarifária. Ainda em 1984, a taxa média tarifária de importação representava 26\%, passando para $16 \%$ em 1988. A liberalização do mercado financeiro também ocorreu na década de 1980 e acabou por reforçar o crescimento da 
concentração econômica dos chaebols.

Em 1991, o governo sul-coreano adotou uma nova onda de políticas estabilizadoras para combater os desiquilíbrios macroeconômicos existentes na economia. O resultado das políticas de maior promoção do Investimento Externo Direto (IED), de liberalização do mercado e de desregulamentação do setor financeiro, então estabelecidas pelo VII Plano Quinquenal de Nova Economia ${ }^{4}$, proporcionaram a admissão da Coréia do Sul na OECD no ano de 1996. No entanto, neste mesmo ano, a economia sulcoreana enfrentou choques econômicos externos e um forte déficit em conta corrente de US\$ 24 bilhões, ou seja, 5\% de seu PIB. Além da desvalorização da moeda em 1995, o endividamento dos 30 maiores chaebols atingiu cerca de 347,5\% em 1996 e 519\% em 1997. A crise financeira desencadeou a falência de diversos conglomerados com forte presença no mercado, como a Kia, o Grupo Hanbo, Haitai, Sammi, Jinro e New-Core Groups, de acordo com Miltons e Michelon (2008).

Assim, a mudança de foco da política industrial, da promoção de ramos industriais estratégicos para a promoção de atividades relacionadas à inovação, enfraqueceu o papel desenvolvimentista do governo sul-coreano. A partir de 2000, a manufatura de alta e média tecnologia e intensiva em conhecimento passou a ser prioridade no país, o qual conquistou a segunda posição em valor adicionado bruto entre os países da OECD no mesmo ano.

\subsection{A Oferta de Tecnologia: Políticas Tecnológicas}

No início do seu processo de desenvolvimento econômico, a Coréia do Sul dependeu fortemente da importação de tecnologia estrangeira para suprir a necessidade de capacidade tecnológica de sua indústria. Os instrumentos das políticas tecnológicas utilizados em 1968 davam prioridade à importação de tecnologias que promoviam as exportações ou que produziam um efeito de difusão em outros setores. De acordo com Lee (2005), as licenças estrangeiras em tecnologia, nos primeiros anos da industrialização, faziam referência à assistência técnica necessária nas empresas para então treinar engenheiros locais aptos à operarem fábricas com contrato “chave de mão”. As restrições ao licenciamento estrangeiro diminuíram já na década de 1970, visto os pagamentos mais altos de royalties fundamentais na aquisição de tecnologias sofisticadas.

Durante as décadas de 1960 e 1970, a mão-de-obra barata sul-coreana foi a principal atração dos investimentos das empresas estrangeiras no país. Porém, com a liberalização das políticas de transferência de tecnologias nas décadas de 1980 e 1990, essas empresas já não estavam mais tão dispostas a colaborar com as empresas sul-coreanas em áreas de maior densidade tecnológica. O licenciamento da tecnologia estrangeira foi forçado a abandonar o seu antigo sistema de aprovação e aderir ao sistema de relatórios com políticas mais brandas. Por sua vez, as revisões das políticas de licenciamento tecnológico de 1978 e 1979 tornaram-se menos restritivas e consentiram a aprovação automática, além de beneficiar todos os ramos industriais do país. Ao passo em que se aproximavam da fronteira tecnológica, os chaebols encontraram dificuldades na aquisição de tecnologias e a transferência destas, as quais encontravam-se no estágio transicional e ainda possuíam patentes em vigor, foi cessada aos poucos pelas empresas estrangeiras. Somente com a ajuda dos institutos públicos de pesquisa e empresas estrangeiras menores é que as empresas sul-coreanas conquistaram aptidões tecnológicas suficientes para aplicar a engenharia reversa avançada em beneficio próprio.

A Coréia do Sul adotou uma política industrial restritiva em relação ao IED no início de seu desenvolvimento tecnológico, que, em conjunto com a política branda de licenciamento tecnológico, era chamada de estratégia desempacotada. Nome dado em razão da aquisição do capital e da tecnologia estrangeiros por diferentes meios. Embora a restrição ao IED fosse aplicada, não houve um desestímulo aos fluxos de capital e de tecnologia. Ao contrário, entre 1960 e 1970 era visível a abundância de investidores estrangeiros no país contra a rara existência de potenciais receptores. Dessa forma, mediante a engenharia reversa, as importações de bens de capital estrangeiros transformaram-se na principal fonte de aprendizado tecnológico das empresas sul-coreanas. Segundo Kim (2005a), no período de 1972 a

${ }^{4}$ O VII Plano Quinquenal de Nova Economia teve início em 1993 e tinha por objetivo elevar o país à níveis de economias avançadas até o ano de 1997. 
1980, a contribuição do IED para o crescimento do PIB da Coréia do Sul foi apenas de 1,3\%, enquanto que no ano de 1971 o valor adicionado da indústria e o valor da produção total contribuíram cerca de $1,1 \%$ e 4,8\%, respectivamente, e 4,5\% e 14,2\% em 1980. As autoridades também gozavam na época do poder de rejeição aos investimentos tidos como investimentos indesejados.

Em contrapartida, a difusão das tecnologias estrangeiras mostra-se tão importante quanto à própria aquisição destas no aperfeiçoamento das aptidões tecnológicas da economia em geral. Os produtores de bens de capital, as empresas de consultoria em engenharia e os institutos públicos de pesquisa foram considerados pelo governo sul-coreano como agentes de difusão especializados. Tais agentes não possuíam a necessidade de serem instigados pelo Estado, o que fez com que fossem comumente utilizados nas décadas de 1960 e 1970, mesmo sem demonstrar muita eficácia no cumprimento de seus objetivos.

Na citação a seguir, Kim (1993) ressalta como o processo de inovação a partir da engenharia reversa, nas décadas de 1960 e 1970, contribuíram para a aquisição de capacidade tecnológica e consequente desenvolvimento do processo de criação presente no SNI sul-coreano mediante a P\&D.

Reverse engineering involves activities that senses the potential needs in the market, activities that located knowledge or products that would meet the market needs, and activities that would infuse these two elements into a new project. Reverse engineering also involved purposive search of relevant information, effective interactions among technical members within a project group and with marketing and production departments within the firm, effective interactions with other organizations such as suppliers, customers, local research institutes and universities, and trial and error in developing a satisfactory result. Skills and activities required in these processes are in fact the same in innovation process in R\&D [Research and Development] (KIM, 1993, p. 369).

Os esforços sul-coreanos em relação à P\&D local aumentaram de acordo com a construção da capacidade tecnológica da Coréia do Sul e conquistaram, progressivamente, mais indústrias intensivas em tecnologia. O setor privado aos poucos assumiu o papel nos esforços de P\&D em resposta ao aumento da competitividade internacional e ao ambiente propício às atividades privadas de P\&D. De acordo com Kim (2005b), a despesa em P\&D da Coréia do Sul cresceu mais que o seu próprio PNB. Em 1971, a participação do P\&D no PNB do país chegava a 0,32\% e em 1996 o número passou para 2,81\%. Já a participação no setor industrial representou 29\% em 1975 e 78\% em 1996. O setor público, ao contrário, observou uma queda em suas despesas totais nacionais em $\mathrm{P} \& \mathrm{D}$, o número atingia $68 \%$ das despesas no ano de 1971 contra apenas 20\% em 1987. Ou seja, o governo tomou iniciativas nos esforços locais em P\&D somente quando o setor privado não tinha capacidade ou mesmo incentivos de mercado para realizar projetos de risco (KIM, 1993).

Dessa forma, dois mecanismos foram amplamente utilizados pelo governo para promover a P\&D nacional: os investimentos diretos em $P \& D$ e os pacotes de incentivos indiretos. O primeiro destinava-se ao desenvolvimento da infraestrutura de Ciência e Tecnologia (C\&T), assim como a promoção de atividades de $P \& D$ nas universidades e institutos de pesquisa do governo. Já o segundo tinha a finalidade de impulsionar o crescimento das atividades de P\&D voltadas para os diversos ramos industriais sulcoreanos, por meio de incentivos indiretos e estímulos financeiros e tributários. Assim, o governo criou e financiou uma ampla rede de Institutos Públicos de Pesquisa Governamental, os IPGS, os quais tinham por objetivo desempenhar um importante papel na P\&D industrial avançada. Em 1966, o Instituto de Ciência e Tecnologia da Coréia (ICTC) foi instituído como um centro técnico integrado com o intuito de apoiar o aprendizado técnico nos diversos ramos industriais. Nos primeiros anos da industrialização, a maioria das despesas totais do país era destinada ao ICTC, para então promoção de um amplo conjunto de atividades em pesquisa aplicada. Ainda em 1966, o governo fundou o Parque Científico de Seul, composto por três institutos de P\&D e três institutos de pesquisa econômica. No ano de 1972 foi a vez do Polo Científico de Taedok, primeira região de alta tecnologia no país, formado por quatorze institutos de pesquisa governamentais, três instituições de ensino universitário e mais de onze laboratórios de P\&D empresariais. A fim de impulsionar a pós-graduação orientada para pesquisa em ciências aplicadas e 
engenharia, o governo inaugurou em 1975 o Instituto Avançado de Ciência da Coréia.

Entretanto, a maior fraqueza do SNI da Coréia do Sul era representada pela falta de interação entre as universidades e o setor privado. Estas culturalmente eram orientadas para o tradicional ensino da graduação, suas instalações apresentavam deficiências e seus membros do corpo decente não possuíam tempo ou recebiam incentivos para realizarem projetos de pesquisas. Ao perceber a dificuldade de reformar a velha tradição educacional do ensino orientado para a graduação, o governo adotou um sistema dual na década de 1970. Tal sistema instituiu atividades de P\&D nas universidades através das escolas de C\&T voltadas para a pesquisa, fundadas então pelo Ministério da Ciência e Tecnologia (MCT) em 1975 e 1995. O governo criou também, em 1989, um esquema de criação de Centros de Pesquisa Científica, Centros de Pesquisa em Engenharia e Centros Regionais de Pesquisa, além de tecnoparques, com o objetivo de acolher laboratórios em conjunto aos centros de pesquisa e as empresas.

A preocupação com futuros problemas das novas áreas de tecnologia também cerca o programa governamental de industrialização, visto que estas áreas apresentam altos riscos de insucesso ou altas externalidades econômicas, exigindo forte apoio governamental por intermédio de Projetos Nacionais de $P \& D$. A adoção dos programas nacionais de pesquisa conferiu participação às universidades e às empresas privadas nos programas governamentais de $\mathrm{P} \& \mathrm{D}$, em concorrência com os institutos governamentais de pesquisa para a aquisição de projetos. O governo também mostrou-se capaz de perseguir tecnologias visadas e de importância estratégica.

Não obstante, as expectativas sob as atividades em P\&D das universidades não foram concretizadas e os institutos de pesquisa governamentais transformaram-se na principal referência em P\&D avançada do país. Os IPGS ajudaram as empresas a adquirirem tecnologia estrangeira nos primeiros anos da industrialização, além de permitir, por meio da pesquisa em conjunto, que as empresas alcançassem conhecimento prévio sobre a tecnologia, assimilando-a e adaptando-a sem demora. O papel destes institutos, contudo, enfraqueceu ao longo do tempo em prol do sucesso dos laboratórios de pesquisa das universidades e dos centros de pesquisa de $\mathrm{P} \& \mathrm{D}$ dos chaebols conquistado em anos seguintes. Logo, 66,8\% do total de pesquisadores no país pertenciam aos centros de pesquisas de empresas em $2011^{5}$, 25,5\% aos laboratórios das universidades e apenas 7,7\% encontravam-se nos IPGS.

Os institutos públicos são carentes em mecanismos de difusão de suas pesquisas para a própria indústria, embora sejam destino da maioria do financiamento público de P\&D do país. Ao contrário destes, os chaebols possuem uma extensiva rede de centros de $\mathrm{P} \& \mathrm{D}$, as quais encontram-se sob influência e controle do mercado e, assim, reagem dinamicamente às suas mudanças ou às mudanças da tecnologia como meio de sobrevivência ao SNI. Os IPGS também foram vistos como a espinha dorsal das atividades de $P \& D$ avançada em razão da ausência de capacidade em P\&D nas universidades nos anos iniciais da industrialização, de acordo com Kim (1993). Por outro lado, nas décadas recentes, as atividades de P\&D nas universidades expandiram-se rapidamente para as áreas de pesquisa básica e de pesquisa aplicada, e, no setor privado experimentaram a expansão nas áreas de desenvolvimento e engenharia. Por conseguinte, os IPGS tiveram o seu o papel enfraquecido e foram espremidos entre as universidades e as empresas. Os institutos devem ajustar o seu papel no SNI sul-coreano, buscando novas oportunidades e os seus próprios nichos, por exemplo, na área de agricultura, saúde pública, meio ambiente, energia nuclear e outros projetos não comerciais.

Em contrapartida, a formação de sistemas nacionais de inovação durante o estágio de criação do desenvolvimento tecnológico, similares aos encontrados nas economias mais avançados, foi considerada como o principal objetivo da política de C\&T da Coréia do Sul e o seu propósito político compreendia o aumento da capacidade de pesquisa das universidades. Em 1993, o governo promulgou uma Lei de Estímulo a P\&D Cooperativa com o intuito de alavancar a pesquisa em cooperação. Já em 1995, o Ministério da Educação aderiu a um novo programa de apoio às universidades orientadas para a pesquisa. Apesar das medidas instituídas, as expectativas em relação ao aumento de capacidade de pesquisa nas universidades novamente não foram atingidas. Para Lee (2005), a rigidez do orçamento governamental impedia o desenvolvimento da capacidade de pesquisa nas universidades por meio de investimentos

\footnotetext{
${ }^{5}$ Para maiores informações, ver Survey Of Research And Development In Korea (2011).
} 
nestas instituições.

Os últimos dados disponíveis sobre a P\&D da Coréia do Sul, divulgados pelo relatório Survey Of Research And Development In Korea (2011) e pela base de dados da OECD (2016), ilustram a situação atual das atividades de pesquisa no país. Em 1990, apenas 1,68\% do PIB sul-coreano era destinado à P\&D, já em 2010 este número aumentou para 3,47\% do PIB e em 2013 alcançou 4,15\%. No entanto, estes dados parecem ser irrisórios, mas evidenciam o grau de importância da presença da P\&D no país. No ranking mundial, a Coréia do Sul está atrás apenas de Israel, com 4,21\% do PIB destinado à P\&D em 2013, e na frente de países como os EUA (2,81\%6), Japão (3,49\%), Finlândia (3,32\%) e China (3,12\%). A taxa de despesa em atividades de P\&D na Coréia do Sul manteve-se estável entre os anos de 1995 à 2012. No primeiro ano, do total de gastos em P\&D no país, 76,26\% foram financiados pelos laboratórios de pesquisa do setor privado e 19,04\% pelo governo. Em 2012, o setor privado foi responsável por $74,73 \%$ da P\&D sul-coreana e o governo por $23,85 \%$. Ainda em 1995 , cerca de $63,6 \%$ do total de pessoas da área de P\&D estavam empregadas no setor privado, 14,4\% no governo, 20,7\% no ensino superior e $1,3 \%$ no setor privado sem fins lucrativos. Os números passaram para, respectivamente, 71,9\%, 8,6\%, 18,2\% e 1,3\% em 2013.

O relatório The Evaluation of Science and Technology Innovation Capacity (2013) frisa que, entre os países com maior número de pesquisadores ${ }^{6}$ em seu território, a Coréia do Sul conquistou em 2013 o $4^{\circ}$ lugar com o total de $288.901^{7}$ pesquisadores no país, atrás apenas dos EUA, Japão e Alemanha. Os sulcoreanos alcançaram também o $4^{\circ}$ lugar referente ao indicador que contabiliza o total de pesquisadores por 10 mil habitantes $^{8}$, em que a Islândia, Finlândia e Dinamarca obtiveram os primeiros lugares. Em relação à taxa de gastos por perfil de atividades de P\&D, do ano de 2000 para 2011, a taxa de gastos em pesquisa básica aumentou 5,5 pontos percentuais. Ou seja, em 2011, 18,1\% do total de despesas em P\&D foram designados para a pesquisa básica, 20,3\% para a pesquisa aplicada e 61,6\% para o setor de pesquisas de desenvolvimento de novos produtos ou processos.

Além disso, segundo a classificação do National S\&T Standard Classification System (apud SURVEY OF RESEARCH AND DEVELOPMENT IN KOREA, 2011), entre as atividades em P\&D da Coréia do Sul que mais dispenderam investimentos nos IPGS no ano de 2011, as três principais áreas de pesquisa correspondem à maquinaria, com 13,39\% do total dos gastos, informação e comunicação com $12,97 \%$ e eletricidade e eletrônicos com 8,8\%. O setor privado segue a tendência dos institutos, porém destinando 29,83\% dos investimentos em P\&D para a área de pesquisa em eletricidade e eletrônicos, $21,68 \%$ para informação e comunicação e $18,43 \%$ para a maquinaria. Ao contrário, o foco das pesquisas nas universidades divergem um pouco dos instrumentos de difusão de tecnologia anteriormente citados. A área de pesquisa de ciência da saúde recebe maior atenção, representando um investimento de 15,91\% do total dos recursos destinados à P\&D nas universidades, contra 8,92\% da área da ciência da vida e 8,68\% de eletricidade e eletrônicos.

Quanto aos incentivos financeiros à P\&D, somente no início da década de 1980 que os empréstimos preferencias foram utilizados como um dos mecanismos de financiamento das atividades de P\&D nacional. Porém, tal mecanismo foi em grande parte maquiado, posto que o governo não disponibilizava vantagens nas condições de financiamento em comparação aos mercados externos e auferia taxas de empréstimo que circundavam entre 6,5\% e 15\%. Outra medida de estímulo financeiro foram os incentivos fiscais fornecidos pelo governo, como os incentivos para investimentos em P\&D; a redução tarifária para importação de equipamentos e suprimentos para P\&D; as deduções das despesas de $\mathrm{P} \& \mathrm{D}$ anuais não-capitalizadas e dos custos de desenvolvimento de recursos humanos do imposto de renda; a isenção de imposto territorial e predial sobre os imóveis utilizados para atividades de P\&D; estímulo à pequenas empresas de base tecnológica; a redução dos custos de comercialização de tecnologias nacionais; a redução dos custos com a introdução de novos produtos; e a promoção de

\footnotetext{
${ }^{6} \mathrm{O}$ indicador desta categoria, número total de pesquisadores, estima o tamanho do pessoal que são profissionais que trabalham na concepção e criação de novos conhecimentos, produtos, processos, métodos e sistemas, bem como aqueles que estão diretamente envolvidos na gestão de projetos.

${ }^{7}$ Pesquisadores em tempo integral de trabalho.

${ }^{8} \mathrm{O}$ indicador capta a participação do pessoal de $\mathrm{P} \& \mathrm{D}$ na população do país, representa o número total de habitantes do país divido pelo número de pesquisadores.
} 
empresas de capital de risco.

A falta de necessidade real de atividades tecnológicas fez com que as empresas não aproveitassem tais medidas nos primeiros anos da industrialização, todavia, as mesmas contribuíram para o rápido crescimento subsequente do investimento em $P \& D$ do setor privado. A fim de suscitar a acumulação de capacidade interna de $P \& D$ em empresas privadas, o governo promoveu a aquisição de tecnologia por meio do IED e de contratos de licenciamento, assim como reduziu barreiras de acesso para o próprio IED. A Despesa Bruta em P\&D (DBPD) da Coréia do Sul atingiu US\$ 9,2 milhões em 1991 e aumentou para US\$ 20,2 milhões em 2000 e US\$ 60,9 milhões em 2012, conforme a OECD (apud THE EVALUATION OF SCIENCE AND TECHNOLOGY INNOVATION CAPACITY, 2013). Já em 2013, o país liderava o ranking mundial de DBPD como porcentagem do PIB, na frente da Finlândia e do Japão.

Entretanto, de acordo com o relatório The Evaluation of Science and Technology Innovation Capacity (2013), a Coréia do Sul perdeu a primeira posição em relação ao indicador despesas em P\&D nas empresas, como porcentagem do valor acrescentado na indústria, para a Finlândia e permanece logo à frente do Japão no ano de 2011. O país detém a $18^{\mathrm{a}}$ posição em investimento de capital de risco e a $13^{\mathrm{a}}$ em network ${ }^{9}$. Ainda em 2011, o IED correspondeu à 2,24\% do PIB sul-coreano, elevando o país à $21^{\text {a }}$ posição entre os países com maiores níveis de IED e, em 2013, para a 27a . Outro indicador importante é a exportação de alta tecnologia, o qual mede o impacto das atividades de P\&D das indústrias intensivas em tecnologia na fabricação de alta tecnologia. Este indicador elevou a posição da Coréia do Sul de quarta maior economia em exportação de alta tecnologia em 2004 para a primeira posição nos anos de 2012 e 2013. Cerca de $25,72 \%^{10}$ do total das exportações sul-coreanas de manufaturados em 2011 foram exportações de alta tecnologia.

Miltons e Michelon (2008) ressaltam, ainda, os estágios e estratégias do desenvolvimento econômico da Coréia do Sul a partir de 1990. Segundo os autores, entre 1983 e 1996, o governo sulcoreano recuperou-se da crise enfrentada na segunda metade da década de 1970 e início de 1980 e deu início ao seu crescimento a partir da expansão das indústrias intensivas em tecnologia e precedente estabilização dos preços. Perante à uma nova crise nos anos de 1997 e 1998, as pequenas e médias empresas foram enfatizadas, assim como a abertura comercial e a promoção da inovação e de empresas de alta tecnologia. A partir de 1999, a economia sul-coreana recupera-se novamente e experimenta um vasto crescimento. Políticas ortodoxas são introduzidas de acordo com o Fundo Monetário Internacional e o país marcha então para uma "economia do conhecimento", com destaque nas indústrias intensivas em alta tecnologia e capital humano.

\section{QUESTÕES POLÍTICAS ATUAIS}

Para o governo da Coréia do Sul, a política de C\&T é vista como o elemento principal de realização de suas metas nacionais de desenvolvimento e da conquista do status de economia desenvolvida e potência mundial. Todavia, a estratégia tradicional de desenvolvimento liderada pelas exportações produzidas pelos chaebols vem sendo questionada em consequência do crescimento moderado do país entre os anos de 2011 e 2012, como também do explícito crescimento da dívida das famílias, do atraso do setor de serviços e da fraqueza existente nas PME. A C\&T têm como propósito garantir o crescimento econômico da sociedade sul-coreana, bem como concentrar estrategicamente os recursos nacionais em pesquisa criativa e em uma sociedade mais justa e progressiva. Por isso, a nova estratégia de crescimento visa promover uma "economia criativa", na qual as empresas de risco desempenham um papel fundamental e a ênfase na coesão social se torne maior, assim como os gastos sociais e o estímulo ao emprego.

\subsection{O Crescimento Verde}

\footnotetext{
${ }^{9}$ A dimensão de rede de network reflete a dinâmica desta dentro de sistemas e o quanto ela ajuda a facilitar a cooperação em fluxo de conhecimento e difusão tecnológica, por exemplo.

10 Último dado divulgado.
} 
Apesar do sucesso do desenvolvimento econômico sul-coreano, a Coréia do Sul sofre desde a década de 1990 com a escassez de recursos e a perda de ritmo em seu crescimento econômico, consequências da forte pressão sobre a degradação ambiental e dos choques externos da economia mundial. Em agosto de 2008, o país adotou o crescimento verde como a sua nova visão para o desenvolvimento, conforme o trecho do discurso do presidente Lee Myung-bak no $60^{\circ}$ aniversário da fundação da República da Coréia:

\begin{abstract}
Green Growth refers to sustainable growth that mitigates greenhouse gas emission and prevents environmental degradation. It is also a new national development paradigm that creates new growth engine and jobs through green technology and clean energy. Green technology combines information and communications technology, biotechnology, nanotechnology and culture technology and transcends the boundaries between individual technologies to achieve a convergence effect. Green technology will help to create numerous jobs and become the new engine driving our future economic growth. Green Growth will bring about another miracle on the Korean peninsula to succeed the "Miracle on the Han River” (Korean National..., 2010, p.111).
\end{abstract}

A excessiva dependência energética em combustíveis fósseis importados e a alta nos níveis de emissão dos Gases do Efeito Estufa (GEE) foram identificados por especialistas nacionais e internacionais à convite do governo como alguns dos desafios a serem vencidos pela nova estratégia. Para implementar tal visão, a Estratégia Nacional de Crescimento Verde foi instituída em julho de 2009 pelo Comitê Presidencial sobre Crescimento Verde, criado no mesmo ano pelo presidente Lee. Esta estratégia representa a visão do presidente em tornar a Coréia do Sul a sétima potência mundial verde em 2020 e a quinta em 2050. Ela envolve ainda três objetivos específicos com o propósito de diminuir a emissão de GEE, bem como aumentar a segurança energética do país, criar novos mecanismos de crescimento por meio de inovações tecnológicas verdes e fomentar um estilo de vida ambientalmente saudável e sustentável entre a população sul-coreana, por meio de dez orientações políticas ${ }^{11}$ então elencadas como metas estratégicas do crescimento verde. O principal objetivo da Estratégia Nacional de Crescimento Verde resume-se em amenizar as alterações climáticas e intensificar a independência energética do país por meio de políticas de redução das emissões dos GEE, diminuição do uso de combustíveis fósseis e de reforço da capacidade de adaptação às mudanças climáticas. A partir de políticas de desenvolvimento de tecnologias verdes e de uma estrutura industrial avançada, por exemplo, novos motores do crescimento econômico podem ser criados.

Entre os países considerados os maiores emissores de GEE do mundo, a Coréia do Sul alcançou a $15^{a}$ posição no ano de 2005 e a nona colocação entre os países da OECD ao gerar 1,3\% do total mundial em emissões. O rápido crescimento econômico do país proporcionou diversas mudanças na intensidade energética e nas emissões dos GEE, que, consequentemente, aumentaram as emissões - GEE per capita em $71,6 \%$ em relação ao período de 1990 a 2005. A economia sul-coreana detinha a $10^{\mathrm{a}}$ posição no consumo de energia mundial em 2009, a quinta posição na importação de petróleo bruto e foi a segunda maior compradora de carvão e gás natural, de acordo com Kim (2011). Em 2009, o governo sul-coreano apresentou o seu projeto de redução de $30 \%$ das emissões em todo o país a partir do corte de $4 \%$ nas emissões de carbono em relação à 2005. Já em 2002, a Coréia do Sul ratificou o Protocolo de Kyoto como um país não-anexo ${ }^{12}$ na Convenção sobre a Mudança do Clima das Nações Unidas. Assim, o corte na intensidade energética, principalmente dos setores econômicos intensivos em energia, e o melhor aproveitamento do gás natural e da energia nuclear foram tidos como a chave do processo de redução de emissões de GEE na economia sul-coreana.

Em 1998, o Comitê Nacional de Economia implementou um acordo voluntário entre as empresas sul-coreanas a fim de promover a eficiência energética no setor empresarial do país. Conforme Jones e Yoo (2011), em troca das baixas taxas de juros nos empréstimos para o fomento de instalações de

\footnotetext{
11 Ver Anexo A.

12 Para o Protocolo de Kyoto, um país não-anexo representa um país em desenvolvimento não comprometido com as metas obrigatórias de redução de emissão de carbono, mas que pode adotar medidas voluntárias para atingir os objetivos do próprio protocolo.
} 
economia de energia e dos benefícios fiscais e suporte técnico, as empresas participantes deveriam especificar seus prazos, estratégias e metas voluntárias de redução dos GEE e de conservação de energia para o então monitoramento por parte do governo. O número de empresas participantes passou de 46 para 1.323 em 2008 e cerca de 58 milhões de toneladas de emissões de dióxido de carbono (CO2) foram reduzidas no mesmo ano. A atuação do governo no mercado internacional de carbono ocorre desde o ano de 2005, por meio do programa Korea Certified Emissions Reductions (KCER). Isto é, certificados de carbono negociáveis no mercado e distribuídos às empresas que obtêm reduções dos GEE em mais de 500 toneladas por ano, mediante a melhoria de sua eficiência energética e de seus processos de produção e dos investimentos no desenvolvimento de energias renováveis.

A Coréia do Sul adotou também programas de eficiência energética para eletrônicos e eletrodomésticos como as normas obrigatórias de eficiência energética e rotulagem de 1992, a certificação aparelho de alta eficiência de 1996 e o programa de espera em redução de eletricidade em 1999. O governo pretende aumentar os níveis de novas e renováveis fontes de energia de 2,4\%, em 2007, para 4,3\% até 2015, 6,1\% em 2020 e 11\% em 2030. Já os impostos ambientais aumentaram de $2 \%$ em 1994 para 2,5\% em 2008, ou seja, cerca de 9,5\% do total das receitas fiscais do governo sul-coreano no mesmo ano. O governo expandiu 2,4 vezes o imposto sobre o diesel e 6,8 vezes o GLP butano entre 2001 e 2007. Assim, o consumo de energia diminui ao passo que os preços do setor ficam mais elevados, o que acaba por promover uma consequente baixa nos níveis de GEE emitidos pelo país, embora limite os subsídios dados à produção de energia que suscitam as emissões representem outra prioridade do plano. O principal subsídio sul-coreano, por exemplo, é destinado à produção de carvão no país e, em 2009, correspondeu somente cerca de 5\% das despesas governamentais relacionadas ao ambiente. A Coréia do Sul possui poucos subsídios reservados aos combustíveis fósseis e tão pouco efetua a proteção de indústrias dependentes destes.

No intuito de implementar o crescimento verde de forma mais sistêmica e consistente, o governo anunciou o Plano Quinquenal para o crescimento verde, que a médio prazo foi o responsável pela definição de orçamentos e tarefas específicas dos ministérios e do governo entre os anos de 2009 e 2013. O plano previa a intenção de um investimento de $2 \%$ do PIB sul-coreano por ano, financiado pelo orçamento público, em programas de crescimento verde, projetos de construção de infraestruturas verdes e também a investigação e desenvolvimento de tecnologias verdes. Além disso, metade de seus investimentos foram destinados à projetos relacionados à mudança climática e à independência enérgica, como as áreas de P\&D nas seguintes tecnologias verdes: a energia solar, as células de combustível, a restauração dos quatro grandes rios do país e o transporte verde.

Em 1992, foi criado o Sistema de Etiquetas Ecológicas para fomentar a informação sobre os produtos ecológicos na sociedade sul-coreana e produzir uma melhoria ambiental no mercado a partir da disponibilização de informações ambientais de fácil leitura nos rótulos destes produtos. Administrado pelo Ministério do Meio Ambiente e o Korea Environmental Industry \& Technology Institute (KEITI), o sistema diferencia os produtos comercializados na Coréia do Sul e facilita a escolha dos produtos ecológicos pelos consumidores. No ano de 2008, U\$15,71 bilhões foram movimentados com a venda de produtos com a etiqueta ecológica, e, de 1997 até 2013 o número de produtos que já possuíam o rótulo passou de 241 para 10.436, segundo o KEITI. Já em 2009, o governo instituiu dois níveis de etiquetas de baixo carbono não obrigatórias. Conforme dados do KEITI, cerca 1.284 produtos e 159 companhias no país foram certificados com a etiqueta de baixo carbono em 2013.

Ainda em 2009, a Coréia do Sul firmou com os EUA uma parceria entre os setores público e privado de ambos os países para o desenvolvimento de novas tecnologias de fontes renováveis de energia, assim como a cooperação bilateral entre universidades, institutos de pesquisa e empresas. Em julho de 2010, o governo sul-coreano inaugurou o Global Green Growth Institute (GGGI), uma plataforma de cooperação internacional sem fins lucrativos, com o objetivo de promover o crescimento econômico de forma ambientalmente sustentável através da troca de boas práticas e de estratégias entre os países sobre o crescimento verde. Etiópia, Brasil, Austrália, Japão, Dinamarca e Emirados Árabes são exemplos de países que já receberam projetos do GGGI.

O crescimento verde da Coréia do Sul almeja alcançar maiores níveis de desenvolvimento econômico ao mesmo tempo em que promove a sustentabilidade ambiental do país, conforme Kang, Oh e 
Kim (2012). A tecnologia verde, principal motor desta estratégia, pode ser representada tanto pelas tecnologias tradicionais limpas quanto pelas novas tecnologias, que contribuem para o crescimento energético e a eficiência dos recursos. Ela move-se ainda na direção de caminhos de desenvolvimento intensivo de baixo carbono que contribuam para os esforços globais de combate às mudanças climáticas. O crescimento verde sul-coreano é visto como a primeira tentativa de um país em desenvolvimento em mudar o paradigma global dominante de crescimento econômico.

\subsection{A Economia Criativa}

Com a posse da presidente Park Geun-hye em fevereiro de 2013, a Coréia do Sul abandonou o velho paradigma econômico então saturado e adotou um novo foco para a sua política desenvolvimentista, a visão de criar um "segundo milagre no Rio Han” em sua economia por meio da “economia criativa”. O governo Park têm priorizado os esforços em inovação e outros motores do crescimento econômico que irão conduzir o país à sua prosperidade futura, ao passo que consolida a transição da economia sul-coreana para uma economia orientada para a inovação avançada.

Em pauta, a economia criativa, de acordo com a presidente Park, representa a ideia de criar novos motores de crescimento e de emprego por meio da "convergence of science and technology with industry, the fusion of culture and industry, and the blossoming of creativity in the very borders that were once permeated by barriers" (CONNELL, 2013, p.1). O termo economia criativa tem como função guiar as políticas econômicas do país, assim como o crescimento verde o fez durante o governo anterior, de Lee Myung-bak. Em 2009, a Coréia do Sul foi o país entre todos os países desenvolvidos que melhor respondeu à recessão ao alcançar uma taxa de crescimento de seu PIB de 6,5\% já no ano seguinte. Com a queda do crescimento do PIB para cerca de 2,3\% em 2012 e a contração da idade economicamente ativa da população, prevista para 2017, os economistas pararam de projetar dias de glória para o crescimento econômico sul-coreano. Segundo o Korea Development Institute, o crescimento deverá cair à uma taxa próxima de $4 \%$ até 2030 . O modelo de crescimento orientado para a exportação utilizado nas últimas cinco décadas no país atingiu os seus limites e a economia sul-coreana entrou em declínio. Em virtude disso, a administração Park reconhece a importância de cultivar na sociedade do país o ambiente necessário para impulsionar a sua inovação. Dessa forma, o governo difunde a agenda da economia criativa no intuito de cumprir o objetivo de democratização econômica e de criação de novos postos de trabalho, ao elevar a taxa de emprego no país para 70\%, além de fomentar o empreendedorismo na economia sul-coreana.

A Coréia do Sul é uma notável economia industrial de alta tecnologia, que estimula empresas líderes mundiais como a Sansung no setor de eletrônicos e a Hyundai em automóveis e construção naval. Em 2013, o país foi a segunda economia com maiores despesas em P\&D entre os países membros da OCDE, a terceira com maior número de professores e, em 2012, a quarta maior fonte de patentes triádicas, além de possuir uma das mais fortes infraestruturas de internet do mundo. O setor de Tecnologia da Informação e Comunicação (TIC) correspondeu à 13,2\% do total do valor adicionado na economia sul-coreana no ano de 2009 e à 6,2\% da taxa de emprego no setor de negócios do país. E em 2014, a Coréia do Sul ficou em primeiro lugar no ranking dos 30 países mais inovadores da Bloomberg (CONNELL, 2013) (STANGARONE, 2014).

Entretanto, embora os gastos com P\&D pelas PME tenham aumentado nos últimos anos, a pesquisa conduzida por elas e pelo setor de serviços ainda é muito baixa se comparadas à P\&D das grandes empresas. Ademais, a colaboração internacional em P\&D também atinge níveis relativamente baixos no país. Segundo Connell (2013) (2014), mesmo que a Coréia do Sul seja a terceira economia com o maior número de patentes de TIC, logo atrás do Japão e dos EUA, ainda deixa muito à desejar entre os países da OCDE quanto às suas taxas em patentes de biotecnologia, nanotecnologia e tecnologias ambientais, setores nos quais a pesquisa básica possui muita importância e que a política sul-coreana aponta como os motores do crescimento econômico. Não obstante, a fragilidade da P\&D das universidades no país é vista como um "gargalo" para o aprendizado da tecnologia. No ano de 2011, apenas $10 \%$ do total de P\&D desenvolvido na Coréia do Sul foi elaborado pelas universidades e, entre o total de patentes desenvolvidas pelo setor privado, somente $5 \%$ são relacionadas à tecnologias 
desenvolvidas nas universidades (OECD, 2014). Por consequência, o foco destas instituições deve abandonar a aprendizagem mecânica para dar ênfase ao ensino, à criatividade e à pesquisa.

O governo Park conseguiu diferenciar-se dos anteriores por meio da forte ênfase que coloca na inovação e no tema da economia criativa como peças centrais de sua agenda política econômica. Assim, no início de sua administração, três ações políticas principais foram tomadas a favor da promoção da inovação. Em primeiro lugar, o governo combinou três agências governamentais, antes separadas, em um novo ministério, o Ministério da Ciência, TIC e Planejamento Futuro (MCTP). O MCTP está encarregado de liderar o desenvolvimento, a coordenação e a implementação de políticas de economia criativa na Coréia do Sul e seus objetivos refletem o Plano de Ação da Economia Criativa ${ }^{13}$, inaugurado pelo governo em junho de 2013, segundo Connell (2014).

O plano têm como meta reforçar a liderança da inovação global do país, bem como criar novos postos de trabalho e indústrias com base na criatividade e na inovação. A eliminação de barreiras financeiras e regulatórias para as PME também fazem parte do plano, no intuito de melhorar o ambiente de financiamento e aumentar o capital disponível para investimento aos empresários. Seis estratégias foram estabelecidas para atingir os objetivos traçados pelo plano: (i) estabelecer um ecossistema para fomentação das startups; (ii) fortalecer o papel das startups e das PME na economia sul-coreana, e, consequente entrada em mercados globais; (iii) criação de novas indústrias como motores do crescimento econômico; (iv) promover a classe mundial talento criativo; (v) reforçar a ciência, a tecnologia e a TIC no país como forma de aumentar a capacidade nacional de inovação; e (vi) impulsionar uma cultura econômica criativa na sociedade sul-coreana.

Com o propósito de incentivar as PME, o governo prometeu aumentar o financiamento público destas em 18\% do orçamento nacional em P\&D até 2017 para o desenvolvimento de tecnologias e priorizar a transferência de tecnologias de universidades e IPGS para as PME. Para integrar de maneira mais eficiente as universidades no processo de pesquisa, a Coréia do Sul deverá reorganizar o financiamento em $P \& D$ através da mudança de foco em $P \& D$ empresarial para a pesquisa básica nas universidades e de subsídios para projetos institucionais. Conforme Stangarone (2014), apenas 15,7\% das pesquisas desenvolvidas nas universidades possuem um financiamento governamental e somente 20,6\% da pesquisa básica é realizada neste tipo de instituição. Em países membros da OCDE, como Japão, Rússia, Hungria e República Checa, a pesquisa básica nas universidades não representa menos de $50 \%$ do total em pesquisas.

O governo ainda discute em sua agenda o apoio para startups que se mostrem prósperas às redes globais e que atraiam a orientação e o financiamento estrangeiro, fundando empresas sul-coreanas por intermédio de empresários estrangeiros. Os empréstimos às PME são efetuados por meio de canais de financiamento como Korea Finance Corpotation (KFC) e Small and Medium Business Corporation (SMBC), os quais contribuíram em 2011 com 85\% do total de estoque de crédito destinado às PME. Estes empréstimos são incentivados pelo Banco da Coréia a partir da transferência de recursos com taxas preferenciais aos bancos do país, porém sujeitos à determinadas condições - alocação de mais de $45 \%$ dos novos empréstimos para as PME, e, no caso de bancos locais a taxa varia para mais de 60\%. A maioria destes empréstimos são efetuados com base em garantias de crédito ou garantias prestadas pelo próprio governo. Logo, o apoio governamental às PME deverá ser limitado e o foco se concentrará nas falhas de mercado e no aumento da eficiência. No longo prazo, as PME se tornaram dependentes da ajuda governamental, que deve voltar a sua atenção para as startups e as empresas de risco sul-coreanas. Assim, a ampliação de empréstimos destinados às PME, mediante as instituições financeiras do país, pode ser vista como parte da solução ao problema.

As leis de falência e a fraca proteção à propriedade intelectual na Coréia do Sul também tornam-se um empecilho aos empresários ao reduzir os incentivos à inovação e à criação de startups. O risco em fundar estas empresas pode ser mitigado através das empresas de capital de risco e da ajuda às startups, no intuito de reduzir os custos de transição associados à elas e criar um ambiente de incentivos adequados. No entanto, o mercado de capital de risco do país encontra-se ainda em fase inicial de desenvolvimento, representando apenas 1\% do financiamento total das PME no ano de 2011. Além disso,

\footnotetext{
${ }^{13}$ Ver Anexo B.
} 
o governo planeja criar um fundo de investimentos, baseado no famoso Fundo Yozma de Israel, com o objetivo de atrair investimento estrangeiro para as startups sul-coreanas e abrir dezessete Centros de Economia Criativa e Inovação nas principais cidades do país até o ano de 2017, para que estes prestem serviços de incubadoras para as startups.

De acordo com Jones e Kim (2014), a regulamentação do mercado de produtos recebe destaque entre os meios de promoção da economia criativa. Se menos restritiva, a regulamentação estimula o investimento privado em atividades inovadoras, a difusão do conhecimento nacional e estrangeiro, além do fomento de novas ideias por meio da entrada de novas empresas na economia. Em contrapartida, no caso de uma regulamentação do mercado de produtos mais incisiva, a inovação e o crescimento econômico acabam sufocados. A Coréia do Sul deve então eliminar todas as regulamentações desnecessárias para o crescimento do país. A liberação das barreias ao comércio e ao investimento internacional promove não somente a própria concorrência internacional, mas acaba por alavancar a economia criativa ao incentivar a alocação mais eficiente dos recursos a partir da difusão do conhecimento e da transferência de tecnologias. Assim, o comércio sul-coreano vem experimentando acordos de livre comércio com a União Europeia (2011), EUA (2012), Canadá (2014) e Austrália (2014). Apesar de possuir o terceiro menor resultado em IED entre os países da OCDE, 13\% do PIB em 2012, o estoque baixo de tal investimento reflete barreiras explícitas ao comércio e outras restrições domésticas, as quais só poderão ser superadas a partir de uma reforma regulatória que atraia maiores níveis de IED ao país.

O incentivo à inovação aumenta as oportunidades de cooperação em tecnologias de ponta entre a Coréia do Sul e países como os EUA. O acordo US-Korea Free Trade Agreement (KORUS), implementado em março de 2012, revela a intencionalidade nesse sentido. Ambos os países estão tão integrados que as políticas de inovação de um afeta, consequentemente, as empresas e as pesquisas no setor inovativo do outro. As disposições do KORUS cruzam com os objetivos da economia criativa do governo Park ao apoiar a cooperação econômica com foco em inovação entre os dois países. O acordo promove, principalmente, o aumento da proteção e execução da propriedade intelectual na Coréia do Sul, com o propósito de alcançar níveis globais de proteção estipulados pela Organização Mundial de Propriedade Intelectual (OMPI) e atender as novas normas de proteção de tecnologias emergentes.

Os acordos de livre comércio, em especial com os EUA e a União Europeia, representam também importantes oportunidades no desenvolvimento da agenda da economia criativa na Coréia do Sul. Com os acordos, as PME e startups sul-coreanas poderão introduzir e aumentar a cota de seus produtos e serviços inovadores em mercados internacionais de prestígio. Benefícios como a redução de encargos, o fomento à um mercado mais competitivo e o alinhamento da Coréia do Sul com os padrões globais poderão ser obtidos a partir da aplicação destes acordos e das reformas regulatórias pretendidas. Deste modo, segundo Connell (2013, p.11)," the government should be looking how most effectively to leverage these agreements [...] to create synergies with its creative economy initiatives and help innovative businesses enter global markets:.

Ao contrário do plano de crescimento verde e de baixo carbono do governo anterior, a presidente Park irá adotar o Plano Nacional de Energia 2014-2018, que promoverá o lado da demanda de eficiência energética e iniciativas de conservação, por meio da ênfase na redução do consumo e da intensidade energética do país. Tal redução será efetuada através do gerenciamento de energia, armazenamento de energia e TIC. Apesar de corresponder a cerca de um terço da geração total de energia da Coréia do Sul, a energia nuclear não será foco da nova política do governo Park e permanecerá em níveis atuais ou poderá sofrer certa baixa devido às recentes consequências da catástrofe de Fukushima e aos casos de corrupção na indústria nuclear do país. As estratégias de longo prazo realçam a importância do gás de xisto norteamericano e chinês, porém no curto prazo a economia sul-coreana dependerá de importações de combustíveis fósseis tradicionais, como o petróleo do Oriente Médio.

É importante que o governo Park reconheça as limitações de seu papel perante a sua capacidade de moldar a economia, assim como evitar intervenções no mercado que sejam capazes de lesar o desafio da rápida mudança tecnológica da economia sul-coreana. Para isso, a presidente Park Geun-hye comprometeu-se em seu governo banir todas as regulamentações desnecessárias do mercado e intitulou a liberalização deste como chave para o fomento do empreendedorismo e, consequentemente, alcance da 
economia criativa. A criação do MCTP, por exemplo, representa uma ótima iniciativa ao limitar a burocracia e aumentar a coordenação das políticas dentro do governo. Já o apoio às PME e aos empreendedores são vistos pela administração Park como potencializadores de crescimento do SNI sulcoreano. Em vista disso, parcerias entres os próprios chaebols e as PME são instigadas pelo Estado como meio de criação de tecnologias inovadoras para o mercado e de redução de diferenças entre as grandes, médias e pequenas empresas sul-coreanas.

\section{CONSIDERAÇÕES FINAIS}

O papel do governo na industrialização da Coréia do Sul foi complexo e essencial para a construção do SNI sul-coreano. O sucesso do desenvolvimento industrial no país deve-se não somente ao desejo industrializador do presidente Park Chung-hee, mas também à um conjunto de medidas adotadas e implementadas durante cerca de três décadas pelo governo sul-coreano. A industrialização do país foi planejada e o investimento no setor industrial realizado por meio de uma visão de longo prazo, a qual promoveu, em primeiro lugar, a criação de uma indústria de base na economia sul-coreana. Até a década de 1970, o governo desenvolveu a indústria química e pesada e, após 1980, conduziu o país à uma nova política com foco na redução da intervenção governamental, na liberalização de setores como o mercado financeiro e o comércio exterior e no incentivo à produção de alta tecnologia.

Os diversificados chaebols foram criados em detrimento da política de substituição de importações e instigados pelo Estado à adquirir a capacidade tecnológica necessária para então assimilar e aperfeiçoar as tecnologias estrangeiras. O uso de engenharia reversa, os esforços e investimentos em P\&D, a criação dos IPGS e os incentivos educacionais da Coréia do Sul promoveram a política de promoção das exportações no país e também o desenvolvimento de indústrias intensivas em tecnologia. Como resultado, a Coréia do Sul ocupa hoje os mais altos índices econômicos e o sucesso em seu desenvolvimento é utilizado como exemplo para as diversas economias em processo de catching-up. Tais medidas citadas comprovam a intencionalidade do governo sul-coreano em transformar o país em uma das maiores potências mundiais. Isto posto, sem o papel desenvolvimentista de seu governo, a Coréia do Sul não teria adquirido em condições naturais os meios necessários para promover de forma rápida e eficiente a sua industrialização. Além disso, teria tido dificuldades para se tornar uma economia avançada ao nível em que hoje ela se encontra. A forte posição do governo frente ao desenvolvimento econômico do país foi fundamental para moldar e construir a base do SNI sul-coreano.

Por outro lado, diante de uma contração da economia, a Coréia do Sul reconheceu a necessidade de reformular as suas estratégias de desenvolvimento. Em 2008, na administração do presidente Lee Myung-bak, o país adotou a política de crescimento verde e baixo carbono, com o objetivo de impulsionar o progresso tecnológico mediante a promoção da eficiência energética. A intensão do presidente Lee era conduzir o SNI sul-coreano para uma economia baseada em tecnologias e produtos verdes, de baixa emissão de GEE, tornando a Coréia do Sul no logo prazo a quinta potência mundial verde em 2050. Entretanto, adotar esta implicou em uma difícil tentativa de mudar o paradigma global dominante de crescimento econômico em benefício da criação de novos motores de crescimento para o futuro, bem como rejeitou a própria estrutura de indústrias intensivas em energia que impulsionaram durante muito tempo o rápido desenvolvimento econômico da Coréia do Sul.

Apesar do foco dado às tecnologias verdes, a presidente Park Geun-hye instituiu em 2013 a orientação econômica da economia criativa, com o propósito de elevar a economia sul-coreana para uma economia de inovação avançada. A própria inovação possui a tarefa, nesta estratégia, de reformular o ambiente de negócios da Coréia do Sul, para que este promova novas descobertas e tecnologias e crie novas oportunidades em mercados antes inexistentes. A economia criativa representa uma mudança no paradigma da economia sul-coreana, em prol da prosperidade, do crescimento futuro e do desejo de se tornar líder mundial no desenvolvimento de produtos, de serviços e de modelos de negócios inovadores. O foco desta política deverá permanecer no fomento de novas indústrias criativas e na criação de um ambiente mais propício possível para a inovação e o empreendedorismo.

A estratégia expansionista de crescimento, baseado em um paradigma de promoção de 
exportações, ocasionou a degradação ambiental e o esgotamento dos recursos naturais da Coréia do Sul. Nessas condições, um dos desafios da economia sul-coreana é o desenvolvimento de uma estratégia de crescimento mais sustentável, que, ao mesmo tempo, incentive a atividade inovativa em P\&D e produza o crescimento da capacidade tecnológica de alta tecnologia do país. Dessa forma, o sucesso da agenda da economia criativa exige do governo um compromisso de longo prazo, muito além do próprio mandato de cinco anos da presidente Park.

Com a rápida industrialização do país, a base do Sistema Nacional de Inovação da Coréia do Sul foi desenvolvida e fortalecida por meio da engenharia reversa, de políticas de incentivo à P\&D e da criação de tecnologias próprias. Todavia, para que o SNI esteja apto para o desenvolvimento de projetos novos e mais sofisticados de alta tecnologia, a Coréia do Sul deverá efetuar grandes investimentos em suas instituições públicas e privadas de pesquisa a fim de promover a inovação em sua economia. Após o amadurecimento do setor inovativo industrial, novos produtos e tecnologias de alto padrão poderão dar continuidade ao progresso tecnológico do país. A evolução da estratégia de uma economia verde e de baixo carbono poderá ser alcançada ao passo que a própria economia criativa avança em seu plano de ação. As políticas defendidas por esta última são essências para a prosperidade do SNI sul-coreano e sua inserção no novo paradigma tecnoeconômico, que, segundo Pérez (2004), corresponde às tecnologias de biotecnologia e nanotecnologia.

\section{REFERÊNCIAS}

ALBUQUERQUE, Eduardo da Motta e. Produção científica e sistema nacional de inovação. Ensaios Fee, Porto Alegre, v. 1, n. 19, p.156-180, jan. 1998.

AREND, Marcelo; FONSECA, Pedro Cezar Dutra. Brasil (1955-2005): 25 anos de catching up, 25 anos de falling behind. [S.I.]: Revista de Economia Política, v. 32, n. 1, p. 33-54, 2012.

CONNELL, Sean. Building a Creative Economy in South Korea: Analyzing the Plans and Possibilities for New Economic Growth. [S.I]: Korea Economic Institute Of America: Academic Paper Series, 10 dez. 2013.

Creating Korea's Future Economy: Innovation, Growth, and Korea-US Economic relations. [S.I]: Asia Pacific: Issues, n. 111, jan. 2014. Mensal. Analysis from the East-West Center.

FREEMAN, Christopher; SOETE, Luc. A economia da inovação industrial. Campinas: Unicamp, 2008. 816 p. (Coleção clássico da inovação).

FREEMAN, Christopher. Technology policy and economic performance: lesson from Japan. London: Frances Pinter, 1987.

The 'National System of Innovation' in historical perspective. Cambridge

Journal Of Economics. Cambridge, p. 5-24. 1995.

GIL, Antônio Carlos; FARLEY, Joshua. Técnicas de pesquisa em economia e elaboração de monografias. 4. ed. São Paulo: Atlas, 2002.

GORDON, José Luis Pinho Leite. Sistema Nacional de Inovação: Uma alternativa de desenvolvimento para os países da América Latina. [S.I.], 2009.

HUTCHINSON, George. Korea's Evolving Energy Strategy: A Different Shade of Green. Korea's Economy 2013, p.9-15, 2013.

JANG, Jin Gyu. S\&T Policy Directions for Green Growth in Korea. STI Policy Review, Seoul, v. 1, n. 1, p.1-22, jan. 2010.

JONES, Randall S.; KIM, Myungkyoo. Fostering a creative economy to drive korean growth. OECD Economics Department Working Papers. [S.I.]: OECD, n. 1152, p.0-0, 26 ago. 2014.

JONES, Randall S.; YOO, Byungseo. Korea's Green Growth Strategy: Mitigating Climate Change and Developing New Growth Engines. OECD Economics Department Working Papers. [S.I.]: OECD, n. 798, 29 ago. 2011.

JOOHO, Whang. Korea’s Green Energy Policies and Prospects. Korea's Economy 2011: A publication of the Korea Economic Institute and the Korea Institute for International Economic Policy. [S.I.], v. 27, p. 49-51, 2011. 
KANG, Sang In; OH, Jin-gyu; KIM, Hongseok. Korea's Low-Carbon Green Growth Strategy. OECD Development Centre. [S.I.]: OECD, Working Paper n. 310, mar. 2012.

KIM, Haeyoung. Korea's Green Growth Strategy: A Washington Perspective. Korea's Economy 2011: A publication of the Korea Economic Institute and the Korea Institute for International Economic Policy. [S.I.], v. 27, p. 25-30, 2011.

KIM, Linsu. Da Imitação à Inovação: A dinâmica do aprendizado tecnológico da Coreia. Campinas: Unicamp, 2005a.

. National System of Industrial Innovation: Dynamics of Capability of Capability Building in Korea. In: NELSON, Richard R.. National Innovation System: A Comparative Analysis. New York: Oxford University Press, 1993. Cap. 11. p. 357-383.

O Sistema Nacional de Inovação Sul-Coreano em Transição. In: KIM, Linsu; NELSON,

Richard R.. Tecnologia, aprendizado e inovação: As experiências das economias de industrialização recente. São Paulo: Unicamp, 2005b. Cap. 11. p. 449-483.

KOREA ECONOMIC INSTITUTE OF AMERICA. Leading Indicators. Disponível em: $<$ http://keia.org/pagefullwidth/leading-indicators> Acesso em: nov. 2014.

Korean National Strategy and Five-Year Plan (2009-2013) for Green Growth. [Editorial] STI Policy Review. Seoul, v. 1, n. 1, p.111-118, jan. 2010.

LEE, Won-young. O papel da política científica e tecnológica no desenvolvimento industrial da Coréia do Sul. In: KIM, Linsu; NELSON, Richard R.. Tecnologia, aprendizado e inovação: As experiências das economias de industrialização recente. Campinas: Editora Unicamp, 2005. Cap. 9. p. 365-393.

LUNDVALL, Bengt-ake. National Innovation System: Analytical Focusing Devise and Policy Learning Tool. Östersund: Swedish Institute For Growth Policy Studies, 2007. 59 p.

National Systems of Innovation: A theory of innovation and interactive learning. Pinter Publishers, Londres, 1992.

MALDANER, Luís Felipe. O Desafio da Inovação: Brasil x Coréia do Sul. Novo Hamburgo, Rs: Feevale, 2006. 197 p.

MASIERO, Prof. Dr. Gilmar. A Economia Coreana: Características Estruturais. In: SEMINÁRIO SOBRE BRASIL E CORÉIA DO SUL. Rio de Janeiro, 2000.

MILTONS, Michelle Merética; MICHELON, Ednaldo. Educação e crescimento econômico na Coréia da Sul. In: ENCONTRO REGIONAL DE ECONOMIA - ANPEC-SUL, Curitiba, 2008.

NELSON, Richard R. As Fontes do crescimento econômico. Campinas: UNICAMP, (Clássicos da inovação), 501p., 2006.

. National Innovation Systems: A Retrospective on a Study. Industrial and Corporate Change. [S.I], v. 1, n. 2, p. 347-374. 1992.

OECD. ECONOMIC SURVEYS: Korea. Organisation For Economic Co-operation And Development, [S.I], jun. 2014.

. OECD StatExtracts. Disponível em: <http://stats.oecd.org> Acesso em: mar. 2016.

PÉREZ, Carlota. Cambio tecnológico y oportunidades de desarrollo como blanco móvil. Revista da Cepal, [S.I], n. 75, p.115-136, dez. 2001.

. Dinamismo Tecnológico e Inclusión en América Latina: Una estrategia de desarrollo productivo basada en los recursos naturales. Revista Cepal. Santiago de Chile, v. 100, p.123-145, abr. 2010.

El reto socio-político del cambio de paradigma tecno-económico. Revista del Banco

Central de Venezuela. Venezuela, v. 2, ago. 1999. ISBN : 0005-4720.

Nueva concepción de la tecnologia y sistema nacional de innovación. Cuadernos de CENDES. Caracas, v.13, n. 31, p. 9-33, abr 1996.

Revoluciones Tecnológicas y Capital Financiero: La Dinámica de las Grandes Burbujas Financieras y las Épocas de Bonanza. México: Siglo XXI, 2004.

PÉREZ, C, SOETE, L, Catching up in technology: entry barriers and Windows of opportunity. In: DOSI, G , FREEMAN, C, NELSON, R., eds. Technical change and economic theory. London: Pinter $p$ 458-479, 1988. 
SEUGN-SOO, Han. Korean Green Growth in a Global Context. Korea's Economy 2011: A publication of the Korea Economic Institute and the Korea Institute for International Economic Policy, [S.I], v. 27, p.13-14, 2011.

STANGARONE, Troy. The Future of Innovation in Korea. International Journal Of Korean Studies. [S.I], p. 157-176. Spring/Summer, 2014.

SURVEY OF RESEARCH AND DEVELOPMENT IN KOREA: Key Figures of Korea R\&D Activities. [S.I]: Korea Institute Of S\&T Evaluation And Planning, 2010. Anual.

SURVEY OF RESEARCH AND DEVELOPMENT IN KOREA: Key Figures of Korea R\&D Activities. [S.I]: Korea Institute Of S\&T Evaluation And Planning, 2011. Anual.

THE EVALUATION OF SCIENCE AND TECHNOLOGY INNOVATION CAPACITY: Composite Science and Technology Innovation Index. [S.I]: Korea Institue Of S\&T Evaluation And Planning, 2013. Anual.

UNCTADStat. Reports. UNITED NATIONS CONFERENCE ON TRADE AND DEVELOPMENT. Disponível em: <http://unctadstat.unctad.org>. Acesso em: 1 abr. 2015.

UN COMTRADE. Database. Disponível em: < http://comtrade.un.org/data/> Acesso em: nov. 2014.

UNESCO SCIENCE REPORT: The Current Status of Science around the World. [S.I], Unesco Publishing, 2010.

UNITED NATIONS DEVELEPMENT PROGRAMME. Human Develepment Reports. Disponível em: < http://hdr.undp.org/en/data> Acesso em: nov. 2014.

WANG, Yuabdi; ZHOU, Zhao. Building an integrative framework for national systems of innovation. Journal Of Knowledge-based Innovation In China. [S.I], p. 160-171. 2011.

\section{ANEXOS}

Anexo A - Estratégia Nacional para o Crescimento Verde

\section{VISÃO}

Tornar-se a $7^{\mathrm{a}}$ potencia mundial verde em 2020 e a $5^{\mathrm{a}}$ em 2050

TRÊS ESTRATÉGIAS
1. Mitigação das mudanças climáticas e independência energética
2. Criação de novas energias para o crescimento econômico
3. Melhoria na qualidade de vida e maior prestígio internacional

\section{DEZ POLÍTICAS PARA ATINGIR AS TRÊS ESTRATÉGIAS}

1. Mitigação eficaz das emissões de gases com efeito de estufa

2. Redução do uso de combustíveis fósseis e maior independência energética

3. Reforçar a capacidade de adaptação às mudanças climáticas

4. Desenvolvimento de tecnologias verdes

5. A "ecologização" das indústrias existentes e promoção de indústrias verdes

6. Avanço da estrutura industrial

7. Engenharia uma base estrutural para a economia verde

8. "Ecologização" da terra, da água e construção de infraestrutura do transporte verde

9. Trazer a revolução verde em nossas vidas diárias

10. Tornar-se um modelo para a comunidade internacional como um líder do crescimento verde

Fonte: Elaborado pela autora a partir de Jones e Yoo (2011). 


\section{METAS}

1 - Criar novos empregos e mercados por meio da criatividade e inovação.

2 - Fortalecer a liderança mundial da Coréia do Sul por meio de uma economia criativa.

3 - Criar uma sociedade na qual a criatividade é respeitada e se manifesta.

\section{ESTRATÉGIAS}

\section{Compensar a criatividade e criar um ecossistema que promova a criação de startups:}

1.1 Proporcionar condições para a fácil criação de novos negócios por meio do investimento, em vez de financiamento bancário

1.2 Patentear ideias criativas

\section{Reforcar o papel das empresas de risco e das PME na economia criativa e sua capacidade de entrar} em mercados mundiais:

$2.1 \mathrm{O}$ governo e as instituições públicas se tornaram o maior cliente para apoiar o pioneirismo dos mercados

2.2 Regulamentações fáceis e aumento do apoio governamental para estimular o investimento.

2.3 Atingir a meta de crescimento para startups, acessando mercados globais.

2.4 Criar um ecossistema que incentiva a cooperação e relações ganha-ganha entre as PMEs e as grandes corporações.

2.5 Construir um sistema que conecta demanda, educação e recrutamento para resolver a escassez de recursos humanos.

\section{Criar mecanismos de crescimento para os pioneiros dos novos mercados e das novas indústrias:}

3.1 Combinar a ciência, a tecnologia e as TIC para energizar indústrias existentes.

3.2 Desenvolver novas indústrias baseadas em software e Internet.

3.3 Criar novos mercados por meio da inovação tecnológica orientada pelo conhecimento humano.

3.4 Empreender novos mercados para descobrir e fomentar novas indústrias promissoras para o futuro.

3.5 Promover a criação de mercado e da convergência da indústria por meio da racionalização da regulação.

\section{Promover o talento criativo global que tem o espírito de superar desafios e perseguir sonhos:}

4.1 Fortalecer o desenvolvimento da convergência do talento criativo

4.2 Revigorar o espírito empreendedor desafiador

4.3 Estimular o avanço no exterior e fluxo doméstico de talentos criativos.

\section{Reforcar a capacidade de inovacão da ciência, da tecnologia e das TIC, que formam a base para a economia criativa:}

5.1 Criar um ambiente de pesquisa autônoma e desafiadora e apoiar a comercialização dos resultados da investigação.

5.2 Empreender mercados da próxima geração mediante o esforço da capacidade de inovação das TIC.

5.3 Estimular a economia regional e reforçar a função de comercialização e de inovação regional das universidades.

5.4 Resolver problemas sociais internacionais por meio da ciência sul-coreana, a tecnologia e as TIC, no intuito de elevar o status da Coréia do Sul.

\section{Promover uma cultura econômica criativa juntamente com o povo coreano:}

6.1 Desenvolver uma cultura criativa que realiza a criatividade e imaginação.

6.2 Fundir ideias sul-coreanas com recursos públicos por meio de um governo 3.0.

6.3 Inovar os métodos de trabalho do governo a fim de realizar uma economia criativa.

$6.4 \mathrm{O}$ centro da economia criativa deve ser o próprio setor privado, e não o governo.

Fonte: Elaborado pela autora a partir de Jones e Kim (2014). 